\title{
Traduire
}

Une autre perspective sur r tr traduction

Revue française de la traduction

$240 \mid 2019$

Quand la politique s'en mêle

\section{Hommage à Maurice Morvillez}

\section{Françoise Wirth}

\section{OpenEdition}

\section{Journals}

Édition électronique

URL : http://journals.openedition.org/traduire/1632

DOI : 10.4000/traduire.1632

ISSN : 2272-9992

\section{Éditeur}

Société française des traducteurs

\section{Édition imprimée}

Date de publication : 20 juin 2019

Pagination : 6-7

ISSN : 0395-773X

\section{Référence électronique}

Françoise Wirth, « Hommage à Maurice Morvillez », Traduire [En ligne], 240 | 2019, mis en ligne le 20 juin 2019, consulté le 14 septembre 2020. URL : http://journals.openedition.org/traduire/1632 


\section{Hommage à Maurice Morvillez}

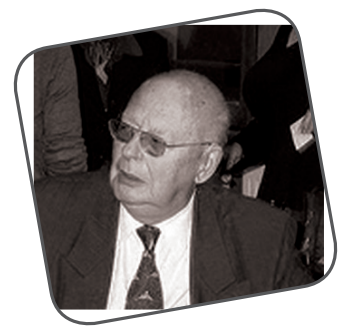

\section{Françoise Wirth}

Maurice Morvillez, fidèle contributeur de Traduire, nous a quittés le 8 janvier 2019.

Maurice était depuis longtemps un pilier de la revue, mais quand je suis entrée à la commission Traduire, début 2007, je n'en savais rien. La revue était alors dirigée de main de maître par Dominique Martin et Marie Gravey, toutes deux, comme moi, de la région Rhône-Alpes.

À l'époque, les relectures d'épreuves se faisaient au crayon, à la main, sur de grandes feuilles envoyées aux relecteurs par l'imprimerie Compédit-Beauregard, qui a accompagné l'aventure de Traduire de 1996 à 2018. Cette tâche était assurée par deux personnes chargées de relire et d'annoter séparément les textes, puis de se concerter par téléphone pour harmoniser leurs commentaires et les reporter sur un seul jeu d'épreuves, renvoyé ensuite par la poste à l'imprimerie. En ce début d'année 2007, pour mes premières relectures d'épreuves, c'est avec Maurice Morvillez que j'ai fait équipe. Quelle formidable façon d'apprendre le "métier» et d'entrer dans la fabrication de la revue! Rien de plus agréable que de travailler avec lui. J'ai pu d'emblée apprécier sa grande gentillesse, son ouverture d'esprit et sa modestie. Adhérente encore récente de la SFT en région, je ne m'étais pas beaucoup intéressée ni à l'histoire du syndicat ni à sa structure centrale. Et Maurice n'était pas du genre à rouler des mécaniques. S'il parlait volontiers de ses traductions 
techniques (traducteur, il était aussi terminologue et ingénieur), pas une fois je ne l'ai entendu rappeler les fonctions qu'il avait occupées à la SFT. Pourtant, difficile de dire qu'il ne s'y était pas investi! Membre du Comité directeur de 1991 à 2003, il a successivement assumé les fonctions de trésorier adjoint, de trésorier, de secrétaire général et de président (en 1997). Le président de la SFT est d'office directeur de la publication de Traduire, mais Maurice est le seul à être directement passé de ce poste à celui de rédacteur en chef, qu'il occupa de 1998 à 2003. II prit alors la suite de Maurice Voituriez... C'est l'époque où Traduire avait ses «deux Maurice». S'il n'était plus rédacteur en chef après 2003, il n'a pas quitté le comité de rédaction pour autant. Depuis 1998, et jusqu'à la fin de l'année 2018, il y a peu de numéros auxquels il n'ait pas contribué. Le compte est vite fait: Maurice a participé à la revue pendant vingt ans!

Quand j'étais rédactrice en chef de Traduire, il me téléphonait de temps en temps. Parfois, je crois, sans qu'il le dise, simplement pour m'assurer de son soutien et me remonter le moral, car la tâche n'était pas de tout repos; l'histoire de la revue n'a rien d'un long fleuve tranquille. Et cela marchait. Après l'appel de Maurice, je me sentais mieux. Comment résister à l'enthousiasme de cet octogénaire, toujours prêt à aller de l'avant, à voir l'avenir avec optimisme et à avaler sa part de travail! Car Maurice était toujours partant malgré les années qui passaient. II s'est mis sans problème à la relecture d'épreuves sur PDF, au maniement de Dropbox et même aux visioconférences! Rien ne semblait devoir l'arrêter. J'avais le sentiment, moi qui ai quitté la commission avant lui, qu'il y serait toujours, qu'il était indestructible. Hélas, voilà que la Faucheuse est passée...

On se souvient, Maurice, et on te remercie de tout ce que tu as fait, pour la revue, pour le syndicat, pour les métiers de la traduction! 